\title{
A Study on Prevalence of Psychiatric Illness in Geriatric Population At A Teritiary Care Hospital.
}

\author{
Dr. B.J.P.Mallika \\ Assistant Professor; Dr.K. Sarada-Assistant Professor; Dr.B.Pushyamisatya-Junior Resident, Department Of \\ Psychiatry, Andhra Medical College,, Visakhapatnam, Andhra Pradesh .
}

\begin{abstract}
Introduction: Elderly constitute rapidly growing proportion of our population. About 10-15\% elderly have mental health problems

Aim: To study the prevalence of psychiatric disorders in elderly persons attending the outpatients department in GHMC

Method: Study was conducted in Out-Patients in GHMC over 6 months and total of 180 patients aged 60-years and above was enrolled. Based on analysis prevalence rates were obtained.

Results: Among the 180 patients, female patients [50.55\%] the male patients (49.37\%) A majority of our patients were from the 60-70 years age group [82.00\%] prevalence of illness was:

Dementia - 56.11\%psychosis - $16.66 \%$ mood disorders- $12.77 \%$, GAD [1.66] others- $7.2 \%$

Conclusion: The study showed a high prevalence of dementia followed by psychosis, mood disorders in the elderly persons who attended GHMC
\end{abstract}

\section{Introduction}

The life expectancy in India has almost doubled from 32 years in 1947 to 63.4 years in $2002^{[1]}$. There is an increased proportion of older people in the total population.Mental disorders influence decisions as to whether or not physical illness can be managed at home, the capacity for self-care and the ability to perform daily tasks of life,cause burden upon family members.

The World Health Organization (WHO) predicts that by 2025, about $75 \%$ of the estimated 1.2 billion people aged 60 years and older will reside in developing countries. ${ }^{[2]}$ The rate of growth will be the highest (around 336\%) in India

The prevalence of dementia is increasing worldwide with population ageing, yet treatments are generally ineffective at slowing progression ${ }^{[15][16]}$. Evidence increasingly supports the terminal course of dementia and requirements for higher levels of care in the later stages of the condition ${ }^{[17]}$ Various urban and rural studies have shown varying rates of dementia prevalence ${ }^{[3-7]}$. Few hospital based studies have been conducted. The present study was undertaken to know the pattern of various common diseases for which the elderly patients sought medical attention in a psychiatric out-patients department in the setting of a tertiary care hospital.

\section{Aims and Objectives}

To study different types of psychiatric illness in geriatric population attending outpatient in government

\section{Materials and methods}

Data of diagnosis of patient aged 60 years and above was collected from outpatient department of government hospital for mental care from December 2015 to may 2016.

\section{Sample characteristics}

IV. Results

180 patients were enrolled in this 6 months study with the ages of the patients ranging from 60 to 80 years.Patients from the 60-70 years age group [82.00\%] and from 70-80 [57.6\%].The overall number of males and females was almost equal [89 (50.55\%) males and 91 (49.37\%) females]

\section{Prevalence of psychiatric illness}

Out of 180 sample about hundred and one members showed cognitive defects [56.11\%], thirty cases psychosis [16.6\%], twenty three cases mood disorders [12.77\%] of which fourteen were of depression[7.77\%] and bipolar mania nine cases [5.11\%] , three[1.66] cases generalized anxiety disorders.Other conditions [7.22\%] 
A Study On Prevalence Of Psychiatric Illness In Geriatric Population At A ...

\begin{tabular}{|l|l|}
\hline Dementia & $\mathbf{5 6 . 1 1 \%}$ \\
\hline Psychosis & $16.66 \%$ \\
\hline \multirow{2}{*}{ Mood disorders } & Depression 7.77\% \\
\cline { 2 - 2 } & Mania 5.11\% \\
\hline Generalized anxiety disorders & $1.66 \%$ \\
\hline Others & $\mathbf{7 . 2 2 \%}$ \\
\hline
\end{tabular}

\section{Discussion}

The current study has shown the average age of patients attending geriatric clinic to be between the age group 60 to 70 years with nearly equal sex distribution that is male [49.37\%] and females [50.55\%] while few other studies showed more male preponderance than females(bhogale et al gupta s et al).

In this study prevalence of dementia was found $56.11 \%$ which shows greater prevalence than other hospital based studies ${ }^{[8-10]}$ which may be more awareness among people there by seeking help by psychiatristsIt can be also may increased cognitive impairments in recent trends than previous times which may need attention. Prevalence of psychosis $16.6 \%$ similar to prevalence from various hospital OPD-based studies which vary between 17 and 33\%. ${ }^{[11-13]}$

Depression was present in $7.77 \%$ of the population which showed lesser prevalence than other studies ${ }^{[8][9][10]}$ which may be as geriatric people are dependent and until it cause significance burden on care givers it may not seek medical attention It can also because of a wrong belief that it is a part normal aging (Katz and Alexopoules,1996).

Only $5.1 \%$ had a diagnosis of bipolar mania.

In the present study, $1.6 \%$ of the persons had Generalized anxiety disorders. Most Indian researchers reported a low prevalence of anxiety disorders in the elderly population. ${ }^{[14][15]}$

\section{Limitations:}

Small sample size and short duration of the study.

\section{Conclusion}

The prevalence of psychiatric morbidity showing a trend for increase in prevalence for cognitive impairment with advancing age. The most prevalent psychiatric disorder in our study was dementia $(56.11 \%)$, followed by psychosis, depression.

\section{References}

[1]. UN population Division: World population prospects, the 2000 revision. New York: United Nations publication; 2001

[2]. Burns A, Lawlor B, Craig S. Rating scales in old age psychiatry. Br J Psychiatry. 2002;180:161-7.

[3]. Ganguli M, Ratcliff G, Chandra V, Sharma S, Gilby J, Pandav R, et al. A Hindi version of the MMSE: The development of a cognitive screening instrument for a largely illiterate rural elderly population in India.Int J Geriatr Psychiatry. 1995;10:367-77.

[4]. Ganguli M, Chandra V, Gilby JE, Ratcliff G, Sharma SD, Pandav R, et al. Cognitive test performance in a community based non demented elderly sample in rural India: The Indo-US cross national dementia epidemiology study. IntPsychogeriatr. 1996;8:50724. [PubMed]

[5]. Pandav R, Fillenbaum G, Ratcliff G, Dodge H, Ganguli M. Sensitivity and specificity of cognitive and functional screening instruments for dementia: The Indo-US cross national dementia epidemiology study. J Am Geriatr Soc. 2002;50:554-61. [PubMed]

[6]. Yesavage JA, Brink TL, Rose TL, Lum O, Huang V, Adey M, et al. Development and validation of a geriatric depression screening scale.A preliminary report. J Psychiatr Res. 1983;17:37-49. [PubMed]

[7]. Sheikh J, Yesavage J. Geriatric Depression Scale; recent findings in development of a shorter version. In: Brink J, editor. Clinical Gerontology: Guide to Assessment and Intervention. New York: Howarth Press; 1986.

[8]. indian j. psychiatry, 1993,35(4), 203-205 geriatric patients attending a general hospital psychiatry clinic g.s.bhogale, c.y.sudarshan

[9]. Indian Journal of Psychiatry, 2002,44(4),326-331

a. geriatric patients attending tertiary care psychiatric hospital yvonne da silva pereira, ajoy estibeiro, rajesh dhlfme\& john fernandes

[10]. Psychiatric morbidity in elderly patients attending OPD of tertiary care centre in western region of NepalPrakashThapa

[11]. Singh GP, Chavan BS, Arun P, Lobraj, Sidana A. Geriatric outpatients with psychiatric illnesses in a teaching hospital setting: A retrospective study. Indian J Psychiatry. 2004;46:14-143.

[12]. Tiple P, Sharma SN, Srivastava AS. Psychiatric morbidity in geriatric people. Indian J Psychiatry.2006;48:8894.

[13]. Pereira YD, Estibeiro A, Dhume R, Fernandes R. Geriatric patients attending tertiary care psychiatric hospital. Indian J Psychiatry. 2002;44:326-31

[14]. Ramachandran V, Menon MS, Murthy BR. Psychiatric disorders in subjects aged over fifty. Indian J Psychiatry. 1979;22:193-8.

[15]. Rao AV, Madhavan T. Geropsychiatric morbidity survey in a semi-urban area near Madurai. Indian J Psychiatry. 1982;24:258-62

[16]. Ferri CP, Prince M, Brayne C, Brodaty H, Fratiglioni L, Ganguli M, et al. Global prevalence of dementia: a Delphi consensus study. Lancet. 2005;366(9503):2112-7. doi: 10.1016/S0140-6736(05)67889-0.

[17]. Mitchell SL, Kiely DK, Hamel MB. Dying with advanced dementia in the nursing home. Arch Intern Med. 2004;164(3):321-6. doi: 10.1001/archinte.164.3.32

[18]. Mitchell SL, Teno JM, Kiely DK, Shaffer ML, Jones RN, Prigerson HG, et al. The clinical course of advanced dementia. 